\title{
A Pilot Program for the Recruitment and Education of Navy Veterans Based on System-level Technical Expertise and Leadership Maturation Developed during Service
}

\section{Dr. Anthony W Dean, Old Dominion University}

Dr. Anthony W. Dean has had several roles in academia. His previous appointments include Associate Professor of Engineering Technology and as Associate Director of the Institute for Ship Repair, Maintenance, and Operations at Old Dominion University (ODU). He is currently on assignment with the Office of the Dean for Sponsored Programs and the Engineering Fundamentals Department, Batten College of Engineering and Technology (BCET) at ODU. His research has focused mostly on control systems (integration and testing) and the reliability and maintainability of complex systems. He has been selected as both a NASA and an ONR Faculty Fellow. He regularly teaches courses in Marine Engineering and in Maintained Systems. Most recently Dr. Dean was on the Headquarters Staff the American Society of Naval Engineers. He received his Ph.D. from the Department of Engineering Management and Systems Engineering, and a B.S. in Nuclear Engineering Technology, from the Batten College of Engineering and Technology at Old Dominion University. Additionally, Dr. Dean received an MBA from the College of William and Mary. Prior to is academic career Dr. Dean was Director of Operations and Business Development for Clark-Smith Associates, P.C., and served as an Electrician in the US Navy aboard the USS South Carolina and the USS Enterprise.

\section{Mr. Connor Schwalm, Old Dominion University}

Connor Schwalm earned his B.S. in Physics from Old Dominion University in 2014. Currently, he is an Graduate Student in the Engineering Management and System Engineering Program at Old Dominion University working towards his M.E. in Systems Engineering with an expected graduation of August 2016. Currently, he works as a Graduate Research Assistant for Dr. Tony Dean on Stern2STEM, a pilot program to increase the student veteran population and retention rates in STEM disciplines. His interests include, Cyber Security Resiliency, Risk and Vulnerability Governance, Academia-Industry Connections, and Broadening Participating in Engineering and Engineering Technology.

Mr. Patrick Sean Heaney, Old Dominion University

Patrick Heaney is a graduate student in the Department of Mechanical and Aerospace Engineering at Old Dominion University.

\section{Dr. Linda Vahala, Old Dominion University}

Dr. Linda Vahala received her B.S..degree from the University of Illinois in 1969, an M.S. degree from the University of Iowa in 1971, and a Ph.D from Old Dominion University in 1983. Her publications include articles in both plasma physics and atomic physics with an emphasis on laser interactions with plasma and with neutral/rare gas collisions. She has presented her work at various international workshops and meetings, both in Europe and in the United States. She is currently Associate Dean and Director of the Engineering Fundamentals Division at ODU. In 1995, she received the Peninsula Engineer of the Year award.

\section{Prof. Yuzhong Shen, Old Dominion University}

Yuzhong Shen received his B.S. degree in Electrical Engineering from Fudan University, Shanghai, China, M.S. degree in Computer Engineering from Mississippi State University, Starkville, Mississippi, and $\mathrm{Ph} . D$. degree in Electrical Engineering from the University of Delaware, Newark, Delaware. His research interests include computer graphics, visualization, serious games, signal and image processing, and modeling and simulation. Dr. Shen is currently an Associate Professor of the Department of Modeling, Simulation, and Visualization Engineering and the Department of Electrical and Computer Engineering of Old Dominion University. He is also affiliated with Virginia Modeling, Analysis, and Simulation Center (VMASC). Dr. Shen is a Senior Member of IEEE. 


\section{Dr. Jennifer Grimsley Michaeli P.E., Old Dominion University}

Dr. Michaeli is an Assistant Professor in the Department of Engineering Technology of Old Dominion University. She received her PhD in Mechanical Engineering from Old Dominion University, her MSc in Ocean Systems Management from Massachusetts Institute of Technology, and her BSc in Naval Architecture and Marine Engineering from Webb Institute. Prior to her arrival to ODU, Dr. Michaeli over 15 years with the Department of Defense and industry as a Naval Architect and Program Manager where she carried out design and engineering, construction and testing for marine vehicles. At ODU, Dr. Michaeli's research and educational interests include topics concerning naval architecture, marine engineering, design, manufacturing and testing of composites and lightweight structures, and engineering multi-criteria decision methodologies. Dr. Michaeli is actively involved in industry-government-academia partnerships to further the advancement of naval and marine engineering. 


\title{
Stern2STEM: A Pilot Program to Increase Veteran Retention and Success in STEM Degree Programs
}

\begin{abstract}
The project, Stern2STEM, aims to advance STEM (Science, Technology, Engineering, and Mathematics) education through the preparation of student veterans to pursue baccalaureate STEM degrees and support the re-employment of these veterans into the Department of Defense (DoD) and the wider defense support industry. The program builds on the training that veterans have received in highly skilled technical areas, both in the classroom and "on-the-job", to develop system level expertise in their respective technical disciplines. Key components of the program include: (1) establishing a mechanism for outreach and recruitment; (2) providing leveling, tutoring, mentoring, and support for students; (3) teaching and learning through proven pedagogical practices and through sound academic advising; (4) partnering with the DoD community to facilitate student career placement in the DoD STEM workforce; (5) providing workforce development for DoD STEM professionals. This paper will discuss the academic challenges that student veterans face while in higher education and the current STEM pipelines as students move through their college to professional careers. The early impact of academic tutoring, professional advising, mentorship, career placement, and recruitment of current service members into STEM disciplines through involvement with Stern2STEM will be discussed. Through Stern2STEM's systematic interventions, the project has the potential to have a significant impact on the broader STEM education community as many of the principles, lessons learned, and tools developed will prove valuable for institutions which have a large population of student veterans.
\end{abstract}

\section{Section I: Introduction}

Military veterans are an underrepresented and largely overlooked population in Science, Technology, Engineering, and Mathematics (STEM) fields. Prior research has demonstrated that engineering attracts students at a lower rate than any other discipline ${ }^{1}$, which is reflected in an aggregate participation rate of about $17.8 \%$ in science and engineering at the associate's and bachelor's degree-levels for military servicemembers and veterans. ${ }^{2}$ Although a large portion of veterans perform technical roles during their military careers, those experiences do not typically lead to technical careers after their military service. This project, Stern2STEM, investigates the transition of servicemembers from military service to baccalaureate STEM degree programs and implements evidence-based interventions that increase participation in STEM fields and support a more successful transition into technical careers. By providing student veterans, who already possess technical STEM training gained in the military, with a strong educational foundation, the program will assist in the closure of the mid-career gap in the Department of Defense (DoD). This talent and competency gap in the $\mathrm{DoD}^{3}$, and STEM disciplines in general ${ }^{4}$, must be addressed by systemic policies and interventions in higher education such as this program, which seeks to increase the quantity and quality of talent seeking placement in STEM careers by focusing on student veterans. Upon graduation, the student veterans who participate in the program will bring a level of leadership, maturity, and technical expertise into the workforce which is greater than traditional graduates of the University. 
The University is uniquely positioned to achieve these aims. It is strategically located in the Hampton Roads region of Virginia which is home to one of the world's largest military populations, with approximately 83,000 active duty military personnel, and has one of the largest concentrations of defense contractors in the United States. Every branch of the military is represented in this region with one or more major command centers within its borders. The University maintains close partnerships with all branches of the military and the maritime, shipbuilding, and repair industries, with many of their representatives serving as members on the University's institutional advisory boards. Each year in the Hampton Roads region, roughly 13,000 military personnel leave their respective branches of service and enter the private sector and/or continue into higher education, which positions the University as a prime location to study the longitudinal effects of intervention to broaden the participation of student veterans in STEM degrees and careers.

The remainder of this paper is organized as follows: Section II reviews the existing literature and programs that are aimed at increasing minority populations in STEM degree fields, Section III describes the objectives and tasks of Stern2STEM, Section IV discusses the current highlights of the program and lastly, Section V draws conclusions.

\section{Section II: Literature Review}

A student veteran is "any student who is a current or former member of the active duty military, the National Guard, or Reserves regardless of deployment status, combat experience, legal veteran status, or GI Bill use". 5 As the number of student veterans increases, the evidence from the literature suggests that the higher education community may not be equipped to support this student population due to a lack of data and research. ${ }^{6,7,8}$ The research that does exist often uses a deficit perspective or was completed by non-veterans who lack knowledge about military experiences. ${ }^{8}$ Although a common theme in the existing literature is the transition from military to post-secondary education ${ }^{9,10,11,12}$, there is little about supporting veterans throughout their time in post-secondary education. Vacchi and Berger created one model for veteran support that includes services, support, transition support, and academic interactions. ${ }^{13}$ In the Hampton Roads Region particularly, research conducted by Sibson showed that first year retention rates for the 2008-2009 and 2009-2010 academic years of G.I. Bill beneficiaries in three higher education institutions (Old Dominion University, Tidewater Community College, and ECPI University) were significantly lower (59.91\% and $60.41 \%$ respectively) than the retention rates for students throughout Virginia (74.15\% and $74.96 \%$ respectively), suggesting a deficiency in these institutions to effectively meet the needs of student veterans. ${ }^{14}$

In 2011 the National Research Council released a report listing the proven, intensive intervention techniques for increasing underrepresented minorities in STEM which include: involvement in summer programs, research experiences with faculty and outside laboratories, professional development activities, academic support, social integration, and mentoring. ${ }^{15}$ As adult learners make up an increasing portion of enrollment at universities, understanding how to increase the performance and retention of this subpopulation is a significant issue facing institutions of higher education. Research on student retention has started to address the unique characteristics and challenges of adult learners, but there are still open questions about the effectiveness of program proposals. $^{14,16}$ There has been significant research related to retention of other minority groups, which may be instructive to future research and program proposals to address adult learner 
retention. ${ }^{15,17}$ Knowledge gained in studies of these other nontraditional student populations may be applicable in the design of programs targeting student veterans.

With widely varying levels of preparation, personal and career goals, and previous experiences, veterans are a unique subset of the nontraditional student population. ${ }^{18,22}$ Within the student veteran subpopulation there are not only a multitude of open research questions, but also difficulty in finding data on student veteran outcomes to provide answers, largely due to student privacy concerns. ${ }^{2,18}$ Several authors have discussed the diversity of student veterans, ${ }^{14,18,22}$ which suggests that any proposed interventions to increase veteran retention must address the diversity of risk factors that this subpopulation faces.

This begs the question, what makes student veterans such a unique subpopulation? As summarized in Table 1, student veterans are diverse along demographic and economic lines. Within this population, women student veterans make up 33\% of National Guard, $31 \%$ of Reservists, $22 \%$ of active duty, and $21 \%$ of veterans. Of today's student veteran population, $48 \%$ of active duty and $47 \%$ of reservists were racial/ethnic minorities. National Guard members in college had the highest incomes $(\$ 47,403)$, while Reservists, active duty, and veterans earned $\$ 34,937, \$ 35,413, \$ 30,538$, respectfully. The average age upon entry into postsecondary education for student veterans is: National Guard - 20, Reserves - 22, Active duty - 22, and Veteran - 25. A large share of student veterans face life circumstances that are associated with postsecondary non-completion such as delayed college enrollment, no high school diploma, part time college enrollment, financially independent, have dependents, single parent status, or fulltime work while in college. Specifically, $60 \%$ of active duty undergraduate students have four or more risk factors associated with not completing college, while the corresponding percentages for veterans, Reservists, and National Guard members are 44\%, 37\%, and 30\%. Fifty-seven percent of Active Duty members and $52 \%$ of veterans have at least one dependent. Forty-two percent of veterans, $36 \%$ of National Guard and reserve members had full-time employment. ${ }^{18}$ According to the Beginning Postsecondary Student Longitudinal Study, 27\% of student veterans did not complete Algebra 2 or higher level math course in high school compared with $16 \%$ of other students $^{19}$, and only $39.4 \%$ of student veterans complete their STEM degree in four years. ${ }^{2}$

Table 1: Diversity of Student Veterans in Higher Education ${ }^{15}$

\begin{tabular}{l|cccc} 
& Active Duty & Reservists & National Guard & Veterans \\
\hline Women & $22 \%$ & $31 \%$ & $33 \%$ & $21 \%$ \\
Minorities & $48 \%$ & $47 \%$ & $40 \%$ & $37 \%$ \\
Income & $\$ 35,413$ & $\$ 34,937$ & $\$ 47,403$ & $\$ 30,538$ \\
Age at Entry & 22 & 22 & 20 & 25 \\
4 or more risk factors & $60 \%$ & $37 \%$ & $30 \%$ & $44 \%$ \\
$\geq 1$ Dependent & $57 \%$ & $46 \%$ & $32 \%$ & $52 \%$ \\
Full-time Employment & $70 \% *$ & $36 \%$ & $36 \%$ & $42 \%$
\end{tabular}

*Some Active Duty students do not work full time if attending school through certain military programs (e.g. ROTC/NROTC scholarship or Green to Gold program). 


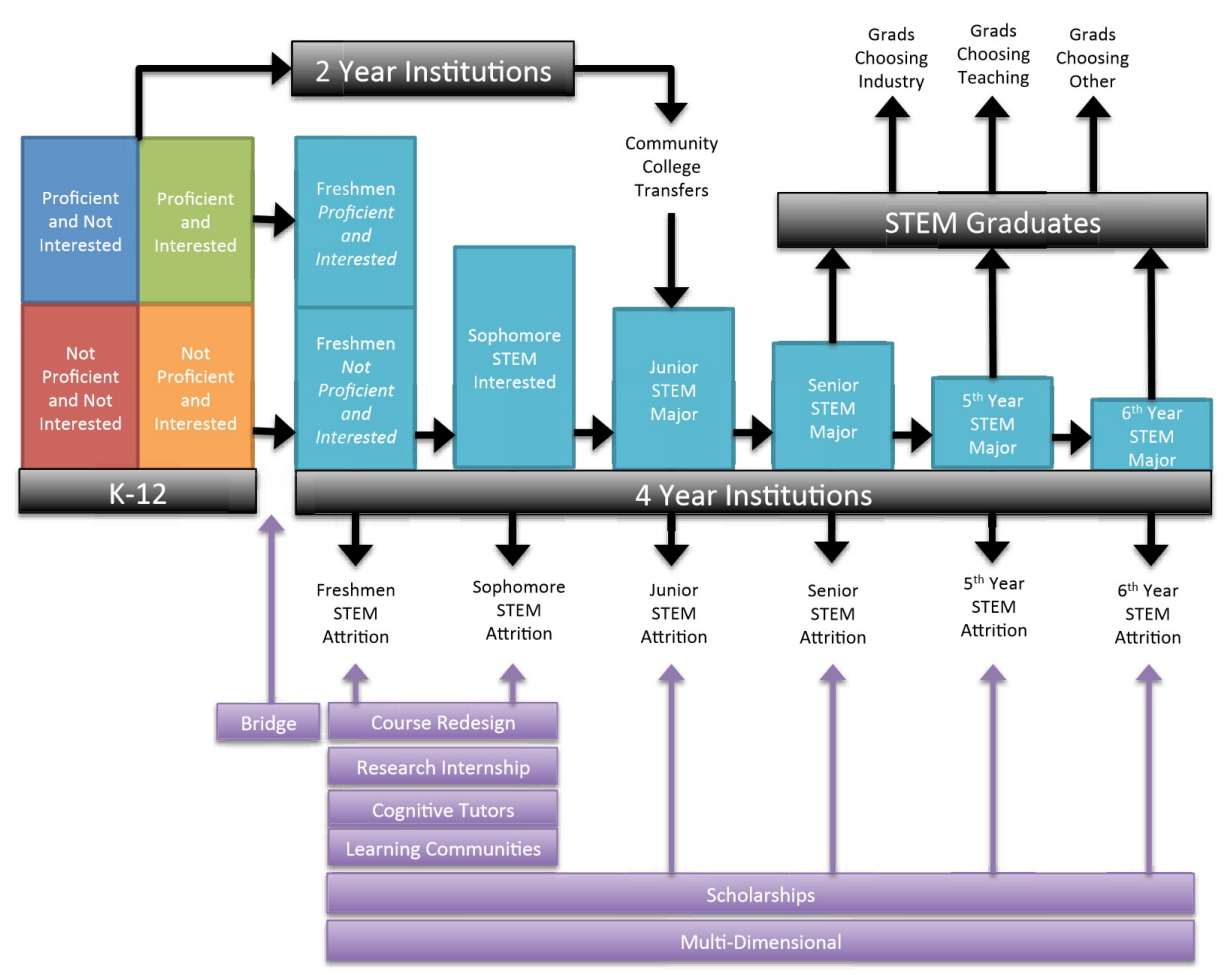

Figure 1: Simplified Representation of BHEF U.S. STEM Education Model. ${ }^{20}$

The current DoD STEM model (Figure 1), developed by the Business-Higher Education Forum $(\mathrm{BHEF})^{20}$, is focused on the traditional K-12 path to college. Upon graduation the DoD is vying with other competitors, including worldwide employers, for the entry-level STEM talent to fill positions in the DoD's civilian workforce. Although many service personnel in today's military work in a wide variety of STEM related fields, the DoD STEM model does not address this group as a viable source of future talent to enter the DoD civilian STEM workforce. The Navy, for example, has made significant investments in time and training to develop its active duty workforce in many technical STEM areas, including nuclear propulsion and electronics. These investments can be as long as two years of training before a sailor is fully capable of performing required tasks. During a typical six-year enlistment, more than a third of that time may be spent on this training and qualification. There is not, however, a concerted effort to develop the Navy's civilian workforce by utilizing the technical expertise and experience of these sailors when they transition into civilian careers and pursue degrees in higher education. With approximately $70 \%$ of the enlisted population below the age of 30, the Navy is seeing significant losses of highly trained personnel whose expertise and experience would contribute greatly to the Navy's civilian workforce. $^{21}$

\section{Section III: Program Components}

After reviewing the current state of research in higher education interventions for minorities, adult, and specifically student veterans, a program was developed to address several of the impediments to success that student veterans typically experience when returning to higher education after military service. The goal of the program, Stern2STEM, is to recruit veterans with experience in STEM-related ratings and support their pursuit of baccalaureate degrees in STEM 


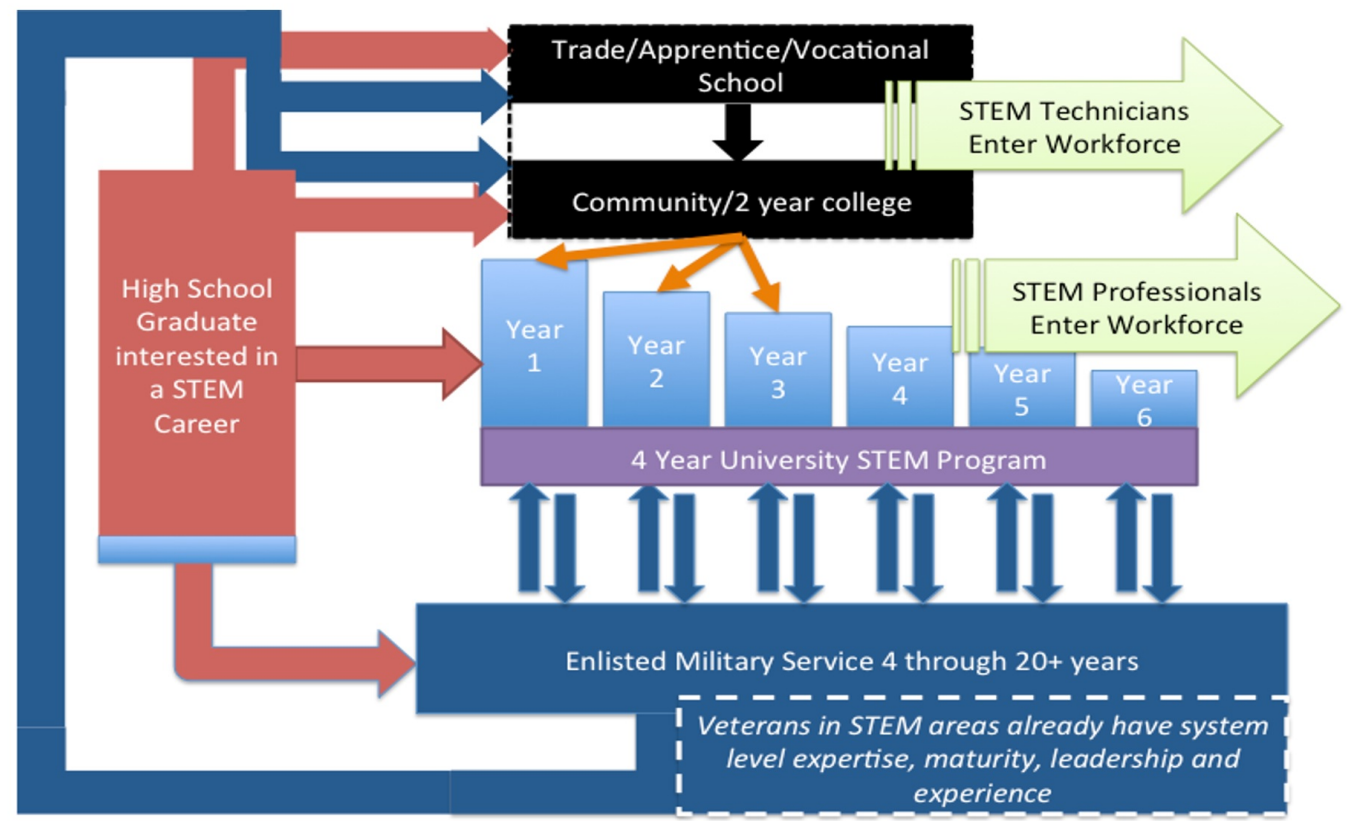

Figure 2: Adaptation of the BHEF U.S. STEM Education Model to address existing servicemembers and other veterans.

disciplines, thereby enabling their re-employment in the defense industry. This structure has built on the current state of research into higher education programs for student veterans, while also developing best practices at the university-level for meeting current and projected human resource gaps in the Navy and Department of Defense. Figure 2 adapts the DoD STEM pathway by recognizing the ability of veterans to address the human resource gaps in the DoD's STEM workforce.

Stern2STEM is composed of five key elements:

1. Establishing a Mechanism for Outreach and Recruitment;

2. Providing Leveling, Tutoring, Mentoring, and Support for Students;

3. Teaching and Learning through Proven Pedagogical Practices and through Sound Academic Advising;

4. Partnering with the DoD Engineering Community to Facilitate Student Career Placement in the DoD STEM workforce;

5. Providing Workforce Development for DoD STEM Professionals.

Through the implementation of this structured system of support, many of the risk factors for non-completion can be addressed for student veterans while taking into account each student's unique characteristics and needs. With intensive academic interventions (leveling curricula, tutoring, remediation via program-developed gaming) and proactive mentoring, many of the academic issues which affect nontraditional students and often lead to non-completion or significant financial burden have been addressed. In addition, the program's focus on workforce development and career placement within the defense industry creates a holistic higher education model for veteran students. 


\section{Section IV: Implementation and Current Findings}

After one semester of implementation, the project team has made notable strides in each of the program's five core components:

Component 1, Outreach \& Recruitment: Initial outreach efforts to veterans on campus have utilized email distribution lists to inform student veterans about the components of the program, specifically highlighting the academic support offered. Toward the end of the Fall 2015 semester, the project team conducted the University's first Engineering College "Active Duty and Veteran Spring Preview Session" with twenty students who started taking courses at ODU in Spring 2016. Participants in the program have also been effective in recruiting fellow student veterans to take advantage of the program. In order to continue reaching a broader proportion of the over 250 veteran students in the University's Engineering College, the project team has started the development of marketing and outreach materials to include a program website which will host information and academic resources for student veterans.

Component 2, Academic Support: The program has provided over 200 hours of individualized tutoring to student veterans during Fall 2015. Two graduate students with specialties in science and mathematics have been tasked with the primary responsibility of tutoring and providing academic support to the program's student veterans. During each session, the tutors utilize Surface Pro 4 tablets and technology-enhanced applications, such as Microsoft OneNote, for reinforcing concepts presented in the student's classes, thus further supporting their understanding and retention. In order to support the academic leveling-requirements of student veterans, the team has started development of the first educational gaming module with the assistance of two doctoral students, which is scheduled to be delivered in beta version in Spring $2016 .^{23}$ These educational games will enable student veterans to remediate foundational academic deficiencies prior to beginning coursework at the University as well as supplement the individualized remedial tutoring sessions for each student.

Anecdotally, the academic support provided to the student veterans has led to an increase in selfperception, academic ability, and final course grades for students who have consistently taken advantage of the program. These student veterans are better positioned to meet the performance and retention objectives of the program. In addition, in seeking to maximize the efficient utilization of veterans' educational benefits the program has provided resources and support for student veterans to fulfill degree requirements through the College Level Examination Program (CLEP) tests and the transfer of credits from the veteran's Joint Service Transcript (JST), which contains transferrable credits obtained during military training. This mitigates one of the risk factors for student veterans, which is running out of educational benefits prior to completion of a degree program due to the requirement to take a significant number of leveling courses.

Component 3, Teaching \& Advising: Upon completion of the leveling course, students will then be integrated into the various ABET-accredited engineering and technology programs offered by the college. However, a strong support system for student veterans will remain in place to provide additional academic assistance, as needed, with year-round/start-to-finish program support from academic success mentors to help ensure degree completion. Student veterans are matched with advisors who have experience working with veterans, who have provided tailored academic advising to forty veteran and active duty students during Fall 2015. 
Component 4, Establish Partnerships: Established relationship with the Wounded Warrior Pilot Program at the Naval Surface Warfare Center Dahlgren Division (NSWCDD), Tidewater Community College, and RTI International (Research Triangle Institute). The ODU American Society of Naval Engineers (ASNE) Student Chapter is one of the largest in the country and provides an additional opportunity for students to enhance their professionalism. The project also seeks partnerships to enable student support needed for the successful project completion. The Veterans Administration, through the VA Work Study Program, has provided two part-time student workers to augment the project, which will enable Stern2STEM to gain additional graduate support in Spring 2016.

Component 5, Career Development: The program will also assist veterans in applying for specific programs (e.g. Pathways, SMART, and Naval Research Enterprise Internship Program NREIP) to provide additional opportunities for the students to gain experience in DoD STEM careers. Thus far, an informational session with a representative from Combat Systems Readiness has been held for program participants which highlighted several of the internship opportunities listed above. As a result of these efforts, five students who are involved in Stern2STEM have accepted Office of Naval Research (ONR) NREIP positions for Summer 2016. One student worker/peer mentor is a DoD SMART recipient.

\section{Section V: Conclusions}

Stern2STEM is making strides in each of its five components and is showing great promise as a way to increase the completion rate for student veterans pursuing a STEM degree. As more student veterans participate in the program, educational gaps in mathematics and science will continue to be closed with mentoring, academic support, and the use of educational tools. Student veterans in the program are also being re-incorporated back into the civilian DoD STEM workforce by participating in summer internships programs such as NREIP, SMART, and Pathways Programs.

In order to evaluate and assess the effectiveness of the project, several metrics will be collected via surveys, interviews between student veterans and advisors, and evaluations of student transcripts. These metrics include:

- number of student veterans that apply to and enroll in the program;

- number of student veterans that enroll in Calculus I after either (1) utilizing the optional Pre-Calculus leveling or (2) take the CLEP or Math Placement Exam;

- number of student veterans continuing toward a STEM Degree from previous year;

- number of student veterans in the program applying to NREIP, DoD SMART, Pathways, DoN, DoD internship programs;

- number of student veterans that apply for a federal position upon completion of the program or apply to broader DoD STEM careers (to include contractors and support);

- number of student veterans that complete the program.

The project has the potential to have a significant impact on the broader STEM education community as many of the principles, lessons learned, and tools developed will prove valuable for institutions which have a large population of student veterans. By developing the materials, 
testing their effectiveness, and providing proof of concept for the recruitment of veterans into the educational pipeline and their re-employment into the wider defense industry, this program will validate a model of systematic interventions and develop scalable best-practices which can serve as the foundation for policies at other institutions of higher education. As the project continues, further validation of the model will take place through analysis of the program's progress on the metrics above, and increased resources will be created to support the academic performance of student veterans.

\section{References}

[1] Ohland, Matthew W., Sheri D. Sheppard, Gary Lichtenstein, Ozgur Eris, Debbie Chachra, and Richard A. Layton. Persistence, Engagement, and Migration in Engineering Programs. Journal of Engineering Education, (2008): 259-278.

[2] Cate, Chris A. Million Records Project: Research from Student Veterans of America. Washington, D.C.: Student Veterans of America, 2014.

[3] Seng, Jocelyn M., and Pamela E. Flattau. Assessment of the DoD Laboratory Civilian Science and Engineering Workforce. Alexandria, VA: Institute for Defense Analysis, June 2009.

[4] Carnevale, Anthony P., Nicole Smith, and Michelle Melton. STEM, Science, Technology, Engineering, Mathematics. Washington, DC: Georgetown University, Center on Education and the Workforce, 2011.

[5] Vacchi, David T. "Considering Student Veterans on the Twenty-First-Century College Campus." About Campus 17, no. 2 (2012): 15-21.

[6] Cook, Bryan J., and Young Kim. From Soldier to Student: Easing the Transition of Service Members on Campus. Washington, D.C.: Lumina Foundation for Education, 2009.

[7] Radford, Alexandria W. Military Service Members and Veterans in Higher Education: What the New GI Bill May Mean for Postsecondary Institutions. Washington, D.C.: American Council on Education, 2009.

[8] Vacchi, David T. "Who are Student Veterans and What Do They Need? Demystifying this Special Population and Framing an Approach to Understanding the Needs of Student Veterans." Scholarly paper presented at the annual conference of the Association for the Study of Higher Education (ASHE), Charlotte, NC, 2011.

[9] DiRamio, David, Robert Ackerman, and Regina L. Mitchell. "From Combat to Campus: Voices of StudentVeterans." NASPA Journal 45, no. 1 (2008): 73-102.

[10] DiRamio, David., and Kathryn Jarvis. "Veterans in higher education: When Johnny and Jane Come Marching to Campus." ASHE Higher Education Report 37, no. 3 (2011): 1-144.

[11] Livingston, Wade G., Pamela A. Havice, Tony W. Cawthon, and David S. Fleming. "Coming Home: Student Veterans' Articulation of College Re-Enrollment." Journal of Student Affairs Research and Practice 48, no. 3 (2011): 315-311.

[12] Rumann, Corey B., and Florence A. Hamrick. "Student Veterans in Transition: Re-enrolling after War Zone Deployments." The Journal of Higher Education 81, no. 4 (2010): 431-458.

[13] Vacchi, David T., and Joseph B. Berger. "Student Veterans in Higher Education," in Higher Education: Handbook of Theory and Research, ed. Michael B. Paulsen, 99-151. New York, NY: Springer, 2014.

[14] Sibson, Kim B. "Impact of the Post-9/11 G.I. Bill: An Examination of Retention of First Year Students Studying in the Hampton Roads Area." Doctoral dissertation, Old Dominion University, 2014.

[15] National Research Council. Committee on Science, Engineering, and Public Policy. Expanding Underrepresented Minority Participation: America's Science and Technology Talent at the Crossroads. Washington, D.C.: The National Academies Press, 2011.

[16] Fincher, Mark. "Adult Student Retention: A Practical Approach to Retention Improvement through Learning Enhancement." The Journal of Continuing Higher Education 58, no. 1 (2010): 12-18.

[17] Dowd, Alicia C., Lindsey E. Malcom, and Elsa E. Macias. (2010). Improving Transfer Access to STEM Bachelor's Degrees at Hispanic Serving Institutions through the America COMPETES Act. Los Angeles, CA: University of Southern California, 2010. 
[18] Molina, Dani, and Andrew Morse. Military-Connected Undergraduates: Exploring Differences Between National Guard, Reserve, Active Duty, and Veterans in Higher Education. Washington, DC: American Council on Education and NASPA - Student Affairs Administrators in Higher Education, 2015.

[19] Molina, Dani, and Andrew Morse. Military-Connected Undergraduates: The Current State of Research and Future Work. Washington, DC: American Council on Education and NASPA - Student Affairs Administrators in Higher Education, 2015.

[20] Business-Higher Education Forum. The U.S. STEM Undergraduate Model: Applying System Dynamics to Help Meet President Obama's Goals for One Million STEM Graduates and the U.S. Navy's Civilian STEM Workforce Needs. Washington, D.C.: The Business-Higher Education Forum, 2013.

[21] Transportation Research Board. Committee on Naval Engineering. Naval Engineering in the 21st Century: The Science and Technology Foundation for Future Naval Fleets. Washington, D.C.: Transportation Research Board, 2011.

[22] Vaccaro, Annemarie. “'It's Not One Size Fits All': Diversity Among Student Veterans.” Journal of Student Affairs Research and Practice 52 no. 4 (2015): 347-358.

[23] Smith, Katherine, Yuzhong Shen, John Shull, Tony Dean, and Jennifer Michaeli. "A Toolkit for Presenting Advanced Mathematics in Serious Games.” Paper presented at IEEE SouthEastCon 2016, Norfolk, VA, April 2016. 